\title{
MATERIAL ANALYSES OF PRESTRESSED CONCRETE BRIDGE FAILURE
}

\author{
Petr ČížEK, Zdeněk KUBOŇ, Ladislav KANDER \\ MATERIAL AND METALLURGICAL RESEARCH, Ostrava, Czech Republic, EU, \\ petr.cizek@mmvyzkum.cz
}

https://doi.org/10.37904/metal.2021.4159

\begin{abstract}
In December 2017 there was a crash of footbridge in Prague - Troja. This failure led to an increase in interest in current status of prestressed concrete stress-ribbon bridges in the Czech Republic and maximum effort to prevent another accident. During next years were identified and subsequently closed other footbridges with proven structural failure of bearing parts. The presented paper describes material analysis of prestressed concrete construction performed on one of observed footbridge. Material analyses confirmed the good material condition except of corrosion attack concentrated in the middle part of the footbridge and especially in the connections between neighbouring segments. Performed analyses revealed fatal decrease of diameter of most strands in the critical middle part of the bridge caused by corrosion enhanced by the maintenance by salting during winter and, most probably, also by two floods in the near past. Main purpose of experimental research was to identify weak spots in construction which contributes to development of corrosion of bearing cables in prestressed concrete construction.
\end{abstract}

Keywords: Prestressed concrete construction, corrosion, bearing cable, metallography, fractography

\section{INTRODUCTION}

In a prestressed concrete stress ribbon bridge high strength steel cables are passed through a series of precast concrete components, the deck assembly of which can be tensioned from stiff abutments. Whereas in a suspension bridge the main load carrying component is the cable with the deck acting as a stiffening element, in a stress ribbon bridge both the cable and the deck can be independently tensioned, thus adding considerable rigidity to the structure [1]. Although such footbridges can be thanks to the relatively light loads easily oversized, they can suffer by climatic and environmental effects, which can in the end shorten their life.

The accident of footbridge in Prague - Troja in 2017 led to increased interest in current status of footbridges, mainly the problem of corrosion of high strength steel bearing cables in prestressed concrete stress ribbon bridges. It is necessary to accent that reinforced concrete construction often contains spaces between concrete and steel strands where corrosion can significantly accelerate.

This paper targets to identify the causes which can lead to fatal failure of footbridge due to corrosion of steel cables in the prestressed concrete construction. Methods used for analysis were based on metallography and fractography assessment of failed strands and evaluation of corrosion damage in different location of strands. Chemical analysis was used for analysis of corrosion products and content of chloride ions and its potential effect on acceleration of the corrosion rate.

\section{EXPERIMENTAL MATERIAL AND TEST METHODS}

Footbridge was composed of prefabricated concrete segments that contained 14 circular channels in the central part for a bearing cables and a pair of troughs on each side for assembly cables. Six bearing cables were stretched in each channel and they were protected by sealing steel tubes at the joints of the segments and at 
the anchorage point. After prestressing, these channels were filled with grout or concrete. Assembly cables placed in the troughs were covered by concrete with minimum thickness $5.5 \mathrm{~cm}$ above the upper row of cables. The tensile strength of strands of bearing and assembly cables is approximately $1800 \mathrm{MPa}[1,2]$. Constructions of footbridges of similar type are well described in [1-3].

Visual inspection revealed heavily corroded strands of bearing cables especially located just to the segment ends where even the protection sealing tubes were destroyed by corrosion, Figure 1 and Figure 2. Detailed view of the corroded and deformed ends of broken cables is stated in Figure $\mathbf{3}$ and the same view of not damaged wires in bearing cables fully covered by injection grout is stated in Figure 4.

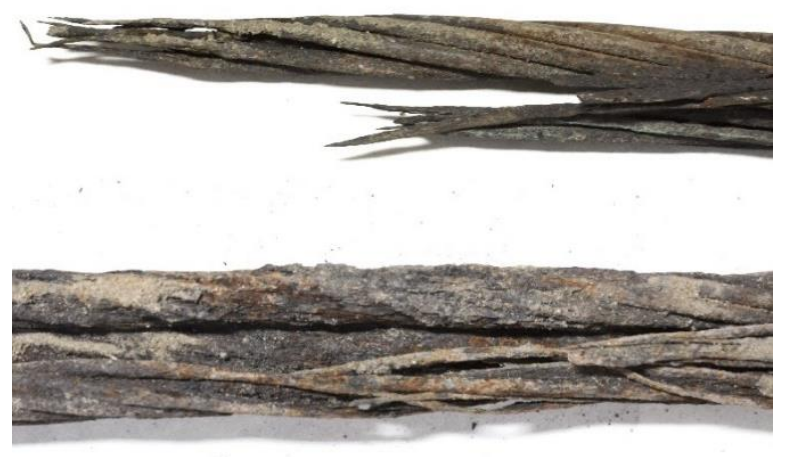

Figure 1 Broken and corroded strands of bearing cables

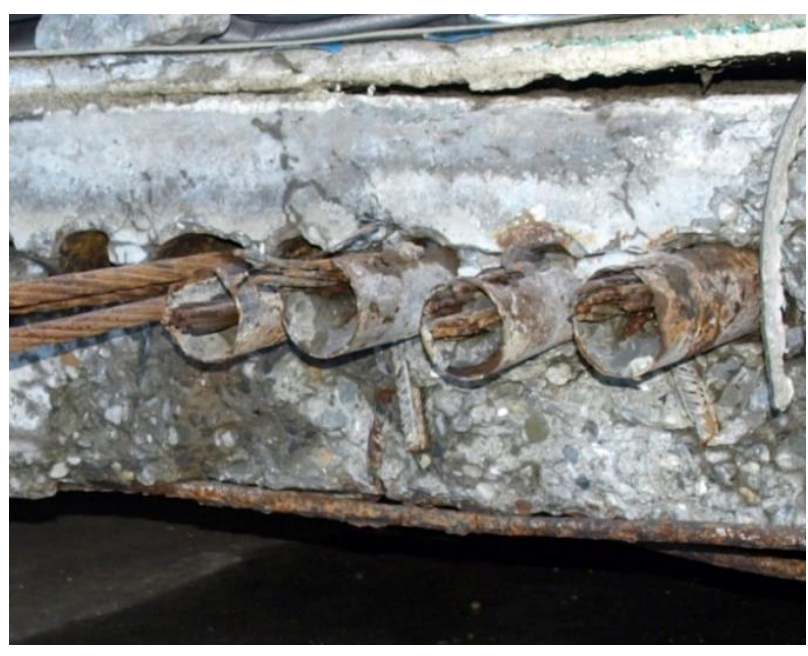

Figure 2 Corroded sealing steel tubes at the end of a segment

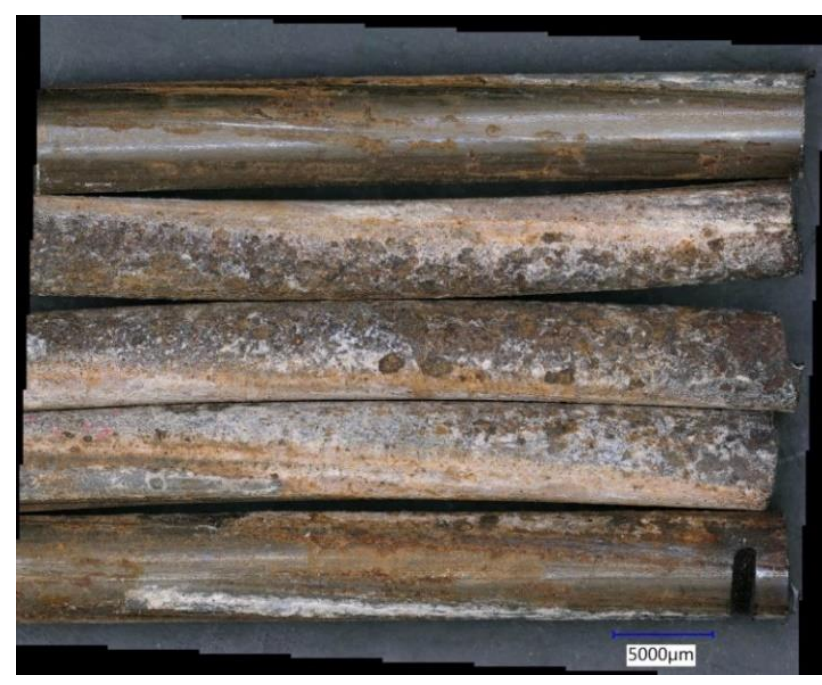

Figure 4 Detail of wires in bearing cables fully covered by injection grout
Figure 3 Detail of broken and corroded wire ends of bearing cable

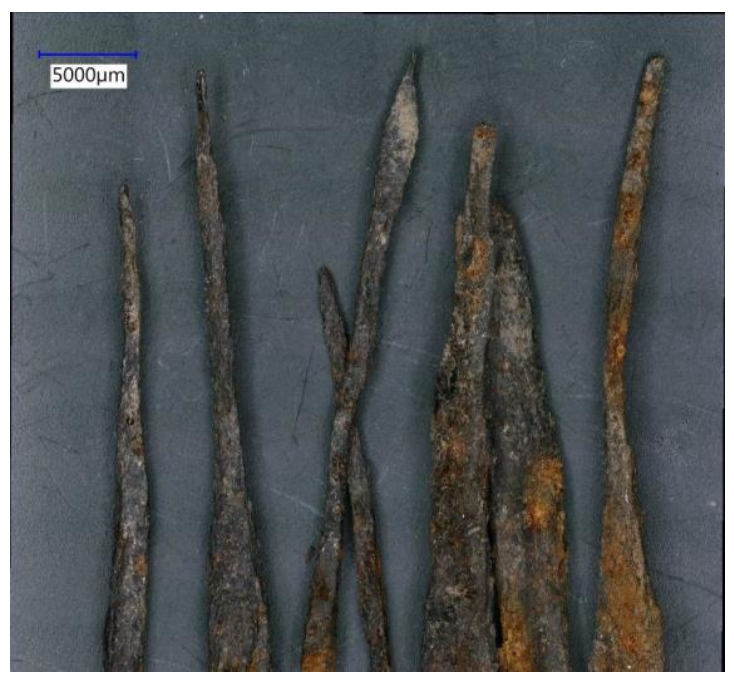

Except of visual analysis of damaged strands of bearing cables was performed also chemical analysis of leachate of sediments on cables, metallographic analysis of damaged and undamaged cables and fractographic analysis of broken strands of cables. 


\section{TEST RESULTS}

Chemical analysis was carried out on a leachate obtained from corrosion products of bearing cables located in the most corrosion damaged but not broken places. The aim of this analysis was to determine $\mathrm{pH}$ of water solution and also the content of chlorides, which was measured by Mohr's titration method. Subsequently was also carried out analysis of chemical composition of corrosion products of cable. The results of these analyses are summarized in Tables 1 and 2.

Table 1 Results of determination of $\mathrm{pH}$ and concentration of chlorides in water leachate

\begin{tabular}{|c|c|}
\hline \multirow{2}{*}{$\mathbf{p H}$} & Chlorides, $\mathbf{C l}^{-}$ \\
\cline { 2 - 2 } & $\mathbf{m g \cdot \mathbf { l } ^ { - 1 }}$ \\
\hline 6.68 & 58.5 \\
\hline
\end{tabular}

Table 2 Results of chemical analysis of corrosion products on wire surface

\begin{tabular}{|c|c|c|c|c|c|c|c|c|c|}
\hline $\mathrm{Fe}_{\text {metal }}$ & $\mathrm{FeO}$ & $\mathrm{Fe}_{2} \mathrm{O}_{3}$ & $\mathrm{MnO}$ & $\mathrm{SiO}_{2}$ & $\mathrm{MgO}$ & $\mathrm{Na}_{2} \mathrm{O}$ & $\mathrm{Cl}^{-}$ & $\mathrm{F}^{-}$ \\
\hline \multicolumn{8}{|c|}{ wt. \% } \\
\hline 1.15
\end{tabular}

From the results of chemical analysis listed in Table $\mathbf{1}$ it is clear that water leachate had neutral $\mathrm{pH}$ and contained very low concentration of chlorides $\mathrm{Cl}^{-}$. In comparison to the limit of chlorides in drinking water that is $250 \mathrm{mg}^{-1}{ }^{-1}$ is the concentration of chlorides around the wire strands relatively low. Chemical composition of corrosion product then corresponds with corrosion of iron and/or steel. Analysis also did not prove presence of increased content of compounds of other elements that could act as accelerators of corrosion process.

Visual examination revealed that the most heavily corroded cables were located approximately in the central third of the total footbridge length where was also the highest point of the footbridge and where the central channels with the prestressed bearing cables were not completely filled with concrete or grout. Metallographic analysis then revealed that cables sampled from undamaged location, where the cable was completely poured in injection mixture were in a very good condition with no significant signs of corrosion, Figure 5. In corroded wire strands taken from the central part of a footbridge where they were not been grouted completely, metallography analysis proved considerable reduction of the load-bearing profile of the wire, thick corrosion layer along the whole wire, heavy internal corrosion and corrosion blunted ends of a wire, Figure 6.
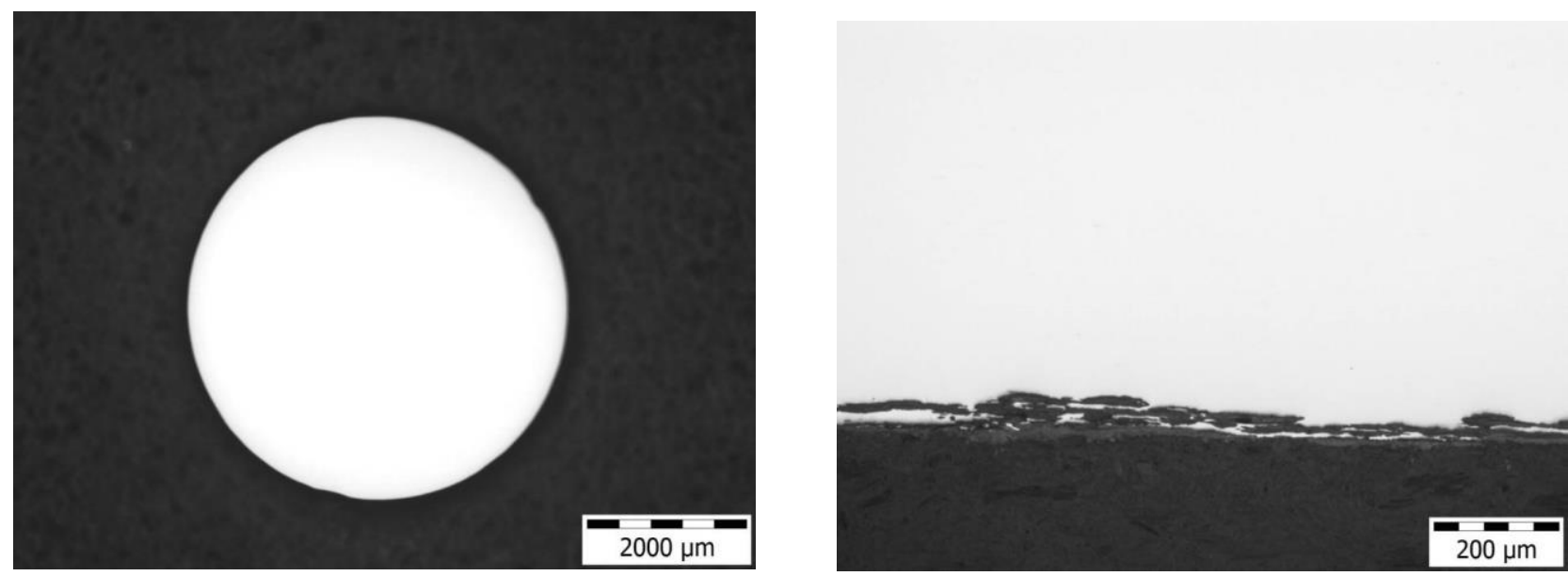

Figure 5 Cross section and very mild corrosion attack of a wire strand in completely injected cable 

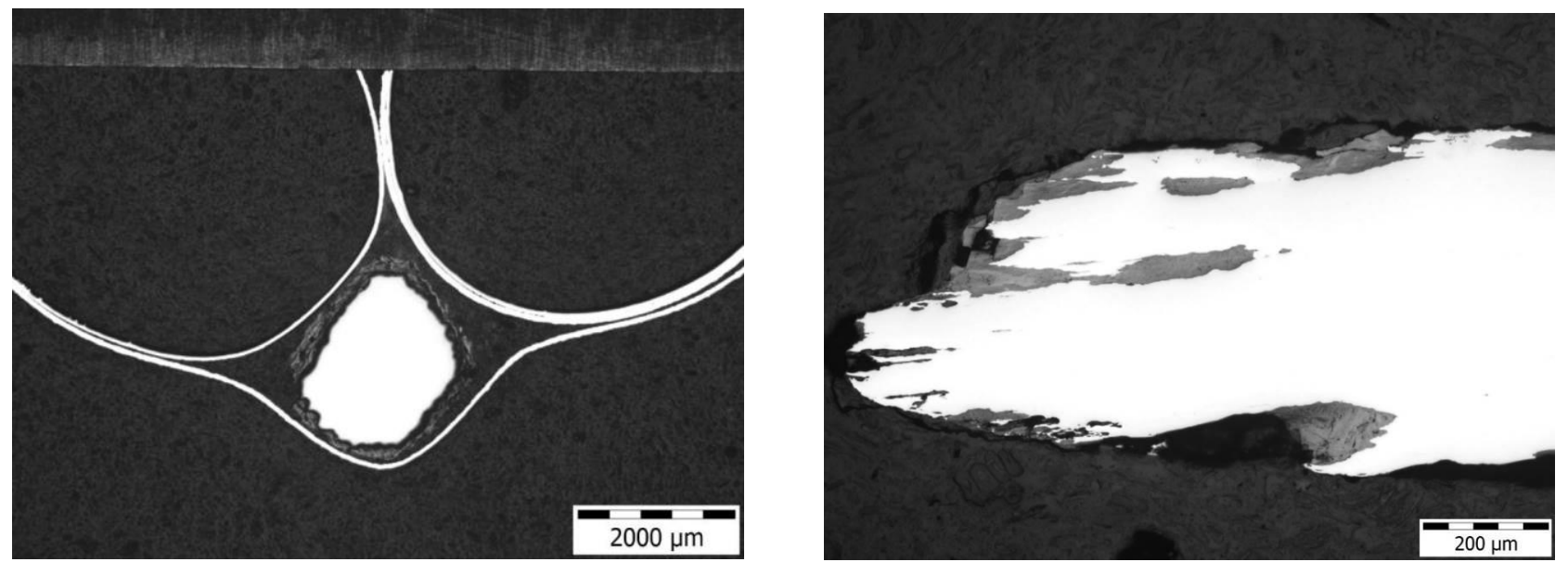

Figure 6 Cross section and heavy corrosion attack of a wire strand in a damaged cable

Microstructure of the wire was pearlitic, but locally there were observed thin films of different contrast (probably ferrite or cementite) elongated in direction of wire drawing.

Fractographical analysis was performed on two samples that visually represented two different types of fracture. Fracture surface of the first specimen had a shape of letter $V$ and was covered by heavy corrosion layer. After cleaning the fracture surface was formed by ductile dimple fracture with elongated dimples, Figure 7. The second analyzed wire was corroded so heavily that its diameter was considerably narrowed and the end of the wire had many longitudinal and transverse cracks, Figure 8. Supposed fracture mechanism was primarily corrosion damage with subsequent break of remaining cross section by fracture from overload.

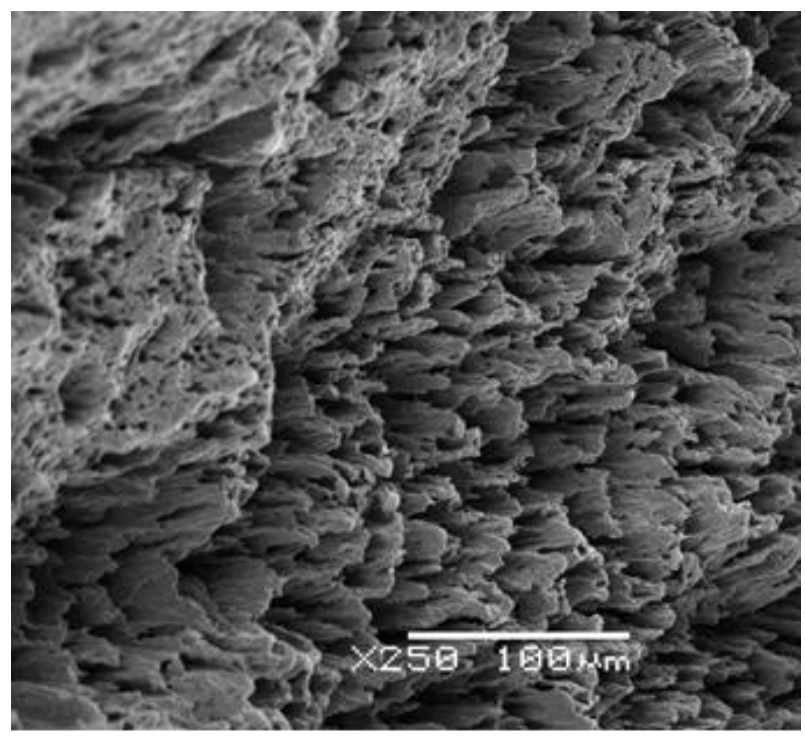

Figure 7 Ductile fracture with elongated dimples

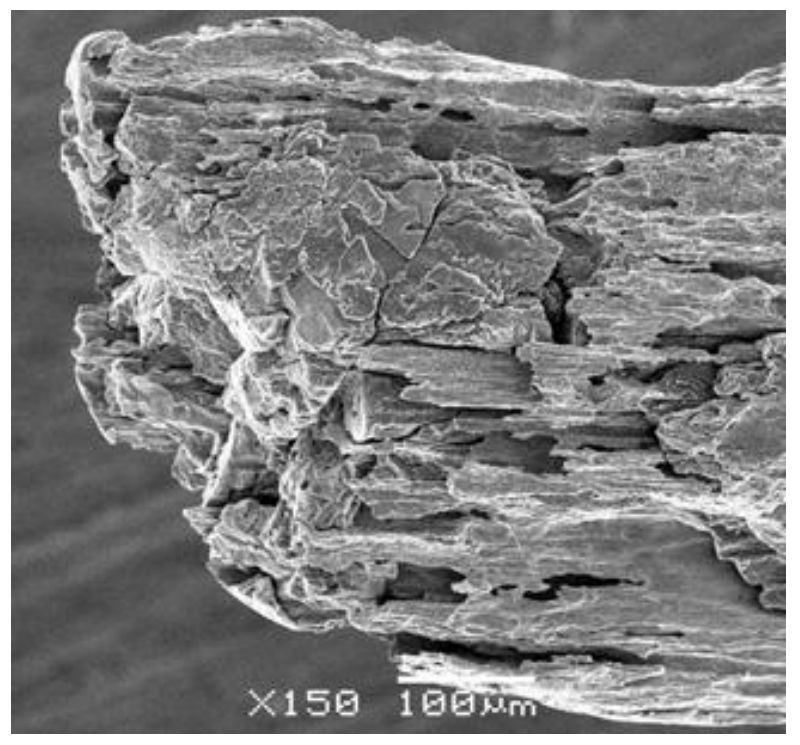

Figure 8 Fracture surface of corrosion damaged wire

Results of metallographic and fractographic analysis confirmed conclusions of visual observations. Bearing cables were locally strongly affected by general corrosion that damaged not only the surface of the wire strands inside the cable but progressed even along the elongated grain boundaries of the cold drawn wires. Such strong corrosion attack with very thick oxide layers means that many strands of cable wires were broken long time before the total collapse of the footbridge. 


\section{DISCUSSION OF RESULTS}

The primary cause of the footbridge collapse was the extensive general corrosion of the entire strands of steel wires in reinforcing prestressed cables. While at both outer thirds of the footbridge these prestressing cables, stretched over the entire length of the footbridge in 14 channels in the central part of the footbridge panels, were fully covered with injection grout and/or cement mixture, in the central third of the footbridge length the cables were either covered insufficiently or not at all. The individual wires in the injection grout protected parts of the footbridge showed only insignificant and shallow corrosion attack, however, in places where the grouting was absent, the wires were locally corroded very heavily. In most cases the areas of intense corrosion corresponded to the joints between the individual panels of the footbridge, where the protection tubes inserted in the end of each panel were also heavily corroded and even perforated. This suggests that water seeping from the surface of the footbridge at the panel joints is responsible for such a corrosion attack. These joints represent in general weak points of the structure where deformations of the stiff concrete panel are transferred with the necessary concentration of stresses and where, therefore, cracks are most likely to initiate. It seems that even sealing steel pipes used to bridge the joints between the individual footbridge panels had not fulfilled the expected protective effect.

Method for calculation of general corrosion rate is stated in standard ČSN EN ISO 9223 and is based on atmosphere conditions like average temperature, relative humidity, mean deposition rate of sulphur dioxide $\left(\mathrm{SO}_{2}\right)$ and mean deposition rate of chlorides [4]. Corrosion loss calculated according this method for the worst corrosion conditions (maximum relative humidity $100 \%$, maximum deposition rates of $\mathrm{SO}_{2}$ and chlorides) increases from $0.4 \mathrm{~mm}$ after the first year of operation through $1.5 \mathrm{~mm}$ after 10 years, $2 \mathrm{~mm}$ after 20 years, up to $3.5 \mathrm{~mm}$ after 50 years of operation. Of course, this method is valid for atmospheric corrosion. However, in the case of corrosion inside closed or near closed prestressed concrete construction has to be supposed formation of cryptoclimate, which may significantly accelerate corrosion rate due to repeated evaporation and subsequent condensation of water. That all in combination with changes of air temperature and deicing of footbridge during winter by salt created suitable conditions for heavy corrosion attack, whereas real rates of corrosion of carbon steel can achieve even as much as $2 \mathrm{~mm}$ per year [4]. Important condition for this corrosion rate is existence of locations where is water presented in both states at air access. This condition is most often met in locations of maximum deflection of footbridge and/or in spaces where the grouting ends.

\section{CONCLUSIONS}

Results of analysis performed on samples obtained from damaged prestressed footbridge confirmed extensive corrosion damage of strands of bearing cables. These bearing cables were stretched in channels passing through all the concrete segments of the footbridge and had to be poured with injection grout. Due to the incompletely fulfilled channels in the central part of the footbridge, the extensive corrosion attack started in the joints between concrete segments, even though protection steel tubes were placed in these joints. The marks of heavy corrosion attack (significantly thinned cross section of whole cables or individual wires corroded in extreme cases into the needle tip) repeated on a cable in the distance corresponding to the length of the bridge segments. Higher risk of water leakage from the broken footbridge surface into the channels just exists in the segment joints. These joints thus represent the weakest point and pose the highest risk of the premature failure of the construction. Therefore, increased attention to regular and periodic inspections focused on these critical areas of the bridge structure.

\section{ACKNOWLEDGEMENTS}

This paper was created in the frame of the Institutional support for long-term and conceptual development of a research organization in 2019, provided by the Ministry of Industry and Trade of the Czech Republic. 


\section{REFERENCES}

[1] STRASKY, J. The stress-ribbon footbridge across the river VItava in Prague. L'Industria Italiana del Cemento. 1987, vol. 10, pp. 638-653.

[2] HART, W. H., LEE, S. K. Modelling and Projecting the Onset and Subsequent Failure Rate of Corroding Bridge Post-Tension Tendons Arising from Deficient Grout. Corrosion. 2018, vol. 74, no. 2, pp. 241-248.

[3] COBO DEL ARCO, D., APARICIO, A. C., MARI, A. R.: Preliminary Design of Prestressed Concrete Stress Ribbon Bridge. Journal of Bridge Engineering. July/August 2001, pp. $234-242$.

[4] ČSN EN ISO 9223: Koroze kovů a slitin - Korozní agresivita atmosfér - Klasifikace, stanovení a odhad. Praha: Úřad pro technickou normalizaci, metrologii a státní zkušebnictví. 2012. 